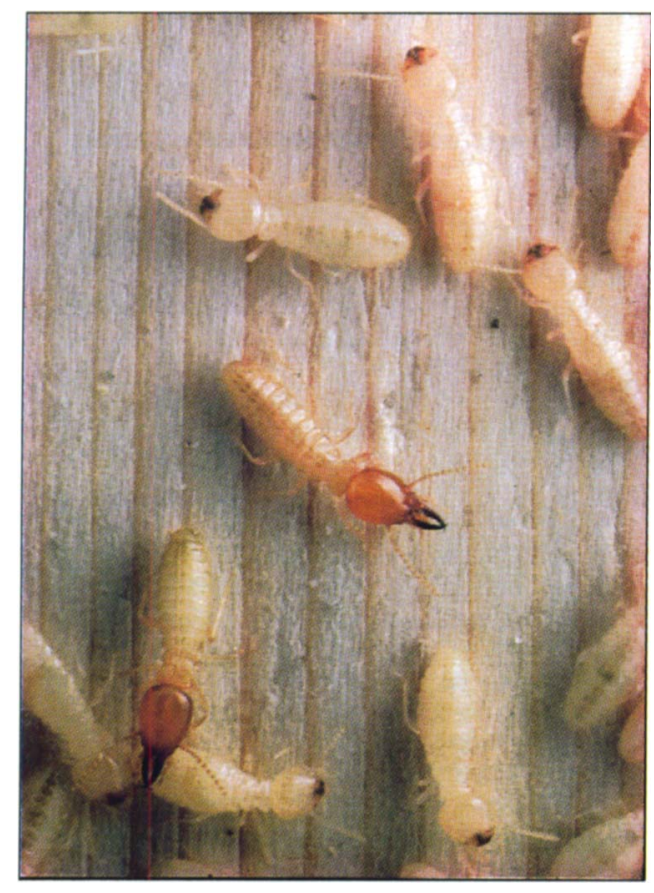

Soldiers are distinguished by the dark head capsule and long mandibles. Workers hatch from eggs laid by the queen and are the only stage that feeds on wood. Colonies can attain $\mathbf{2}$ million workers within 5 years.

The first reported case of a nonnative termite species being introduced and established in California was the Formosan subterranean termite, which was discovered in San Diego County in 1992. Because this termite can exact tremendous damage within a relatively short time, the affected area was defined and an attempt was made to eradicate it. Intensive baiting with the insect growth regulator hexaflumeron over 12 months appears to have eliminated the original infestation. New infestations have recently been discovered in and around homes about 1/4 mile away, and winged Formosan subterranean termites have been caught nearly 3/4 mile away. Measurements of workers and soldiers and dating of damage suggest that the new colonies are 6 to 8 years old, and that new colonies established from winged reproductives before baiting took effect at the original site. If left unabated, this pest may become increasingly more serious in California.

\title{
Ravenous Formosan subterranean termites persist in California
}

\author{
Michael K. Rust $\sqsupset$ Donald A. Reierson $\square$ Eileen O. Paine \\ David Kellum $\square$ Karl Haagsma
}

In February 1992, Formosan subterranean termite was discovered in $\mathrm{La}$ Mesa, a residential community approximately 10 miles east of San Diego. The infestation was estimated to be approximately 10 years old (Atkinson et al. 1993). This age corresponds to a time that a family living at the epicenter of the affected area brought wood and potted plants with them when they moved from Hawaii. Formosan subterranean termite is common in Hawaii, and one or more colonies were probably transported to California in the family's belongings. This species was misidentified for several years after its introduction. We documented Formosan subterranean termite from seven adjacent core area properties in La Mesa.

In 1995 we reported that the Formosan subterranean termite, Coptotermes formosanus Shiraki, had become established in La Mesa

(Haagsma et al. 1995). Since then, we have eliminated the original termite infestation, but the termite appears to have spread to an adjacent area before elimination was complete. As with virtually all species of termites, the hidden nature of young $C$. formosanus colonies makes them especially difficult to detect and identify. Damage by young colonies is often localized and may go unnoticed for years.

\section{Distribution and impact}

The Formosan subterranean termite is native to mainland China and has spread to tropical and subtropical areas of the world, primarily by com- merce (Su and Tamashiro 1987). In the United States, C. formosanus is a major structural pest in Hawaii and is established in at least seven southeastern states, where it causes extensive damage. It is becoming increasingly economically important wherever it has become established. It is currently the most destructive termite in Florida and Louisiana. Once established in an area, C. formosanus can exact tremendous damage within a relatively short time. Large colonies have reportedly caused significant damage to homes within 6 months of detection, and have rendered homes unlivable within 2 years. Besides attacking homes, $C$. formosanus also ravages utility poles, boats and even dead portions of living trees.

\section{Termite life cycle}

Like other termites, the Formosan subterranean termite is a social insect living in colonies with a division of labor between specialized castes. $C$. formosanus typically nest in the ground, but sometimes build aerial colonies with no ground contact if sufficient water is available. They have even been found flourishing in Florida and Hawaii on the rooftops of highrise apartment buildings.

Seasonally, new kings and queens form as the colony matures. Winged males (kings) and females (queens) from the same or different colonies leave the nest to mate and begin a new colony. These new reproductives are $\tan$ in color, have long wings, and are called alates. As with most termites, 


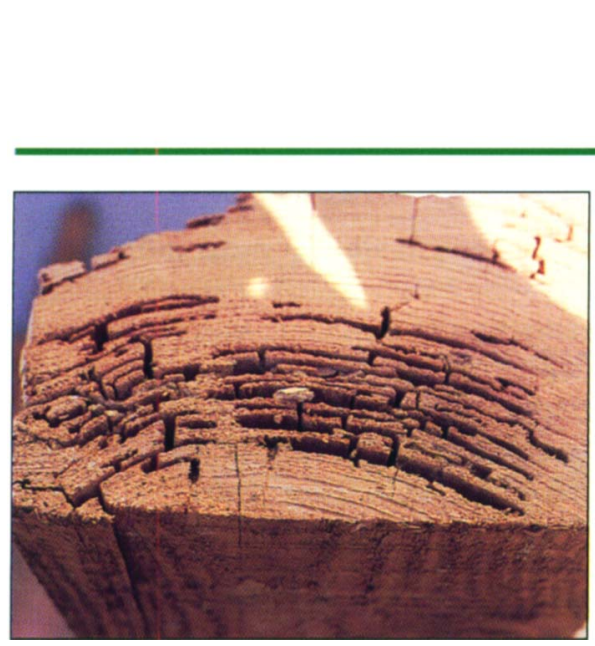

Termite damage to a large beam that supported the floor of an infested home at La Mesa. Large colonies have reportedly rendered homes unlivable within 2 years.

only a small fraction of the alates that leave the colony are successful at starting new colonies.

In San Diego, sporadic mating flights of $C$. formosanus occur from May to September. They always occur in the early evening and on days during which the daytime temperature exceeds $88^{\circ} \mathrm{F}\left(31.1^{\circ} \mathrm{C}\right)$. Workers hatch from eggs laid by the queen and are the only stage that feeds on wood. Colonies can attain 2 million workers within 5 years (Higa 1981). Like most species of termites, C. formosanus also has a defensive caste called a soldier.

\section{Effect of bait}

A new bait formulation (Recruit) found to be highly preferred by $C$. formosanus in other parts of the country was substituted for the original bait reported by Haagsma et al. (1995). The original bait was fed upon to some extent by termites in La Mesa, but the new formulation was clearly more palatable. Bait containing $0.5 \%$ hexaflumeron - an insect growth regulator that prevents termites from developing new cuticle at the time of molting - was presented in four ground stations and two stations in an infested mature pepper tree from late February to July 1996 . There was termite feeding in all six stations. During these 5 months, the termites consumed a total of 360 grams of bait (1.8 g active ingredient). By July 23, no termites could be found at any bait station, trap, nor other location within the core area of the seven properties on which $C$. formosanus was originally found in 1992.

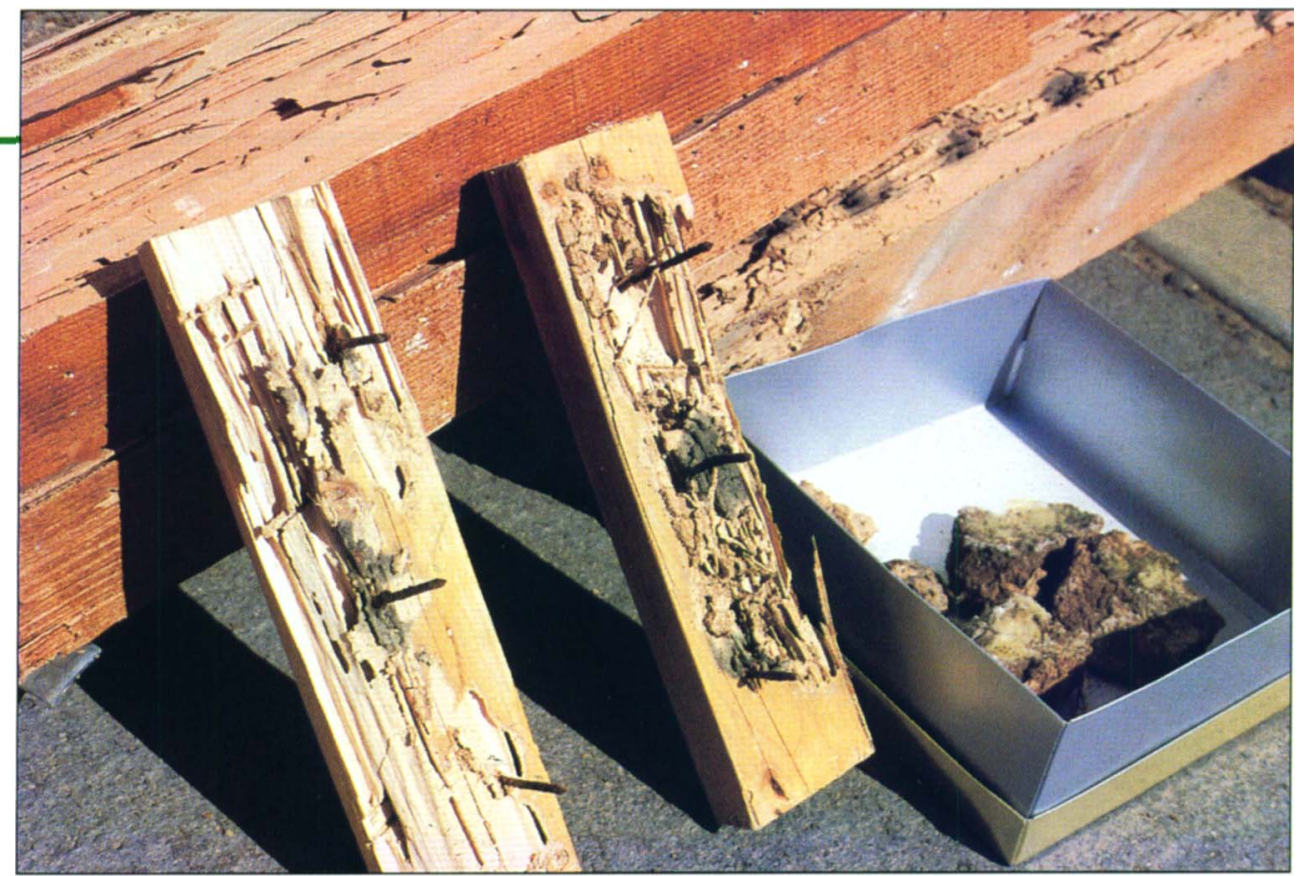

Damaged beams and Formosan termite carton (nest) in box.

Subsequent monthly ground surveys and monitoring with sticky traps for alates and with wood stakes for workers suggest that the baiting eliminated $C$. formosanus from the originally affected area.

Baiting has the advantage of minimizing pesticide use. A termite colony is killed if worker termites feed on strategically placed bait and pass it among themselves and to the queen and soldiers. Conventional liquid termite treatments kill only the termites that they contact, and they protect structures by providing a repellent and toxic barrier.

A small amount of foraging on hexaflumeron bait may be sufficient to eliminate a termite colony. Since hexaflumeron is slow acting, affecting the insects when they molt, feeding on the bait may continue long after the amount needed to kill the colony has been consumed. In Florida, an estimated population of 1.2 million Formosan subterranean termites was eliminated after feeding on only 51.8 grams of bait ( $259 \mathrm{mg}$ ai), and a population of the eastern subterranean termite, Reticulitermes flavipes (Kollar), estimated at 476,000 individuals, was eliminated with as little as 0.8 grams of bait (Su 1994).

Determining the effectiveness of control of subterranean termites is problematic because of the highly sea-

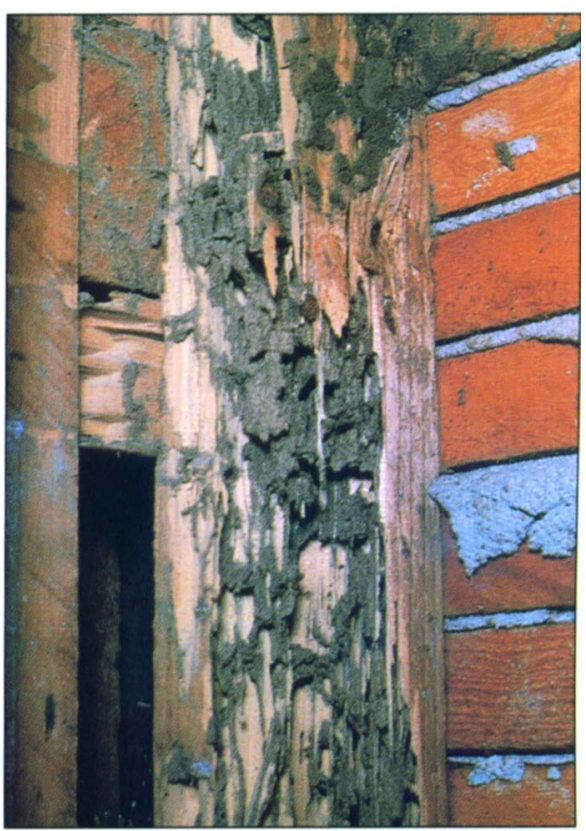

Wood damage and typical mud carton material packed in the wood by Formosan subterranean termites.

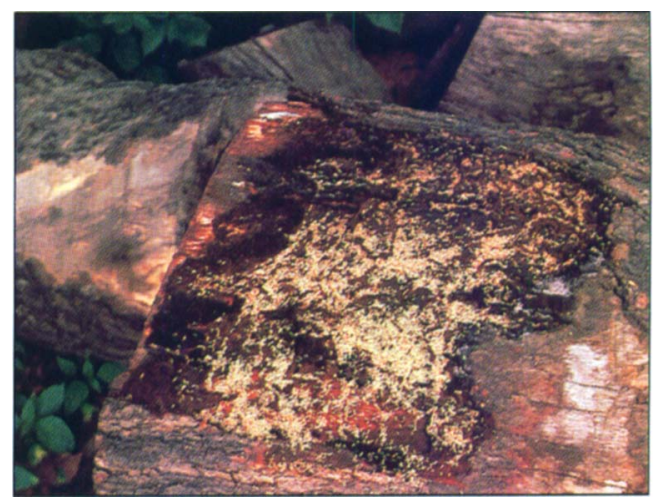

Cut firewood infested with Formosan termites. 


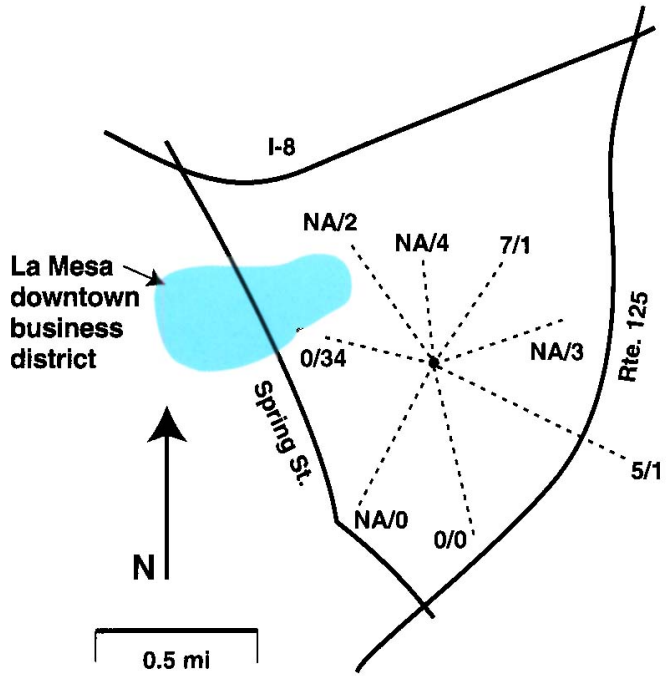

Fig. 1. Distance and direction of light traps from the original infestation and the number of alate Formosan subterranean termites trapped in 1995 and 1997. NA = not available; 1995/1997.

sonal and cryptic nature of termites. Damage often goes undetected. We have been further hampered at the La Mesa site because we had no precise pretreatment population estimates. Despite extensive monitoring with up to 100 wooden stakes driven into the ground on the property and around each home where alates were captured, less than $3 \%$ of the stakes were ever attacked by termites. Sticky cards and light traps were more useful tools to locate new or previously undetected infestations.

Trapping data suggested the presence of a second ground infestation at least 1 year before the infestation was discovered. Thus, the success of baiting was judged by visual inspection, the lack of termite activity in the area, and a decrease in the number of alates trapped.

After finding no C. formosanus activity for several months within the baited area, a colony was discovered in November 1996 approximately 1/4 mile from the original infestation, just beyond the border of the area we were monitoring. The fact that we continue to find no C. formosanus in the original baited area strongly suggests that colonies in that area were eliminated or have been suppressed to such an extent that they have been undetectable for many months.

However, finding a colony outside the baited area is disconcerting because it suggests that sources of infestation persist nearby.

\section{Trapping alates}

Beginning in 1992, swarms of alates of $C$. formosanus were monitored in $\mathrm{La}$ Mesa with sticky traps hung on porch lights at 10 homes near the site where the termites were first discovered. Alates tend to fly to lights in the early evening. We expected most alates to be caught on traps nearest the center of infestation. Alate monitoring in 1993 was expanded to include 69 properties. In 1995, commercial fluorescent light traps for insect collection were installed at each of four sentinel locations about $1 / 2$ mile from the affected homes, in locations where alates from the epicenter would have a good chance of encountering the traps. In 1997, we added another four light traps some of which were up to a mile away (fig. 1).

Continuous monitoring of temperature, humidity and rainfall was done in La Mesa since 1993 and we correlated alate trap catch to that monitoring. Figure 2 shows alate trap counts and average monthly maximum temperatures in La Mesa for selected dates during the study in the core area.

Major swarming of $C$. formosanus occurred in June or July, only when daytime temperatures exceeded $88^{\circ} \mathrm{F}$ $\left(31.1^{\circ} \mathrm{C}\right)$. There was no relationship to rainfall. Lesser swarming events occurred for up to 5 months following the major swarm.

Initial analysis from the original isolated infestation on seven properties showed that most trapped alates were caught within 500 feet of where they emerged, but a few were caught up to 900 feet away. The number of alates collected in the core area has steadily declined since 1993, in spite of more intensive trapping between 1994 and 1997. This reduction is consistent with the lessened foraging activity in our ground traps, and is an indication of the impact of hexaflumeron bait in the original epicenter of infestation. We have examined alate trap data by quadrants and distance from the original infestation because of the discovery of a second established population of $C$. formosanus recently found nearby, but outside our baited and monitored area.

We collected C. formosanus alates in light traps as far as 0.7 miles from the original infestation. Light traps are apparently more effective at trapping swarming $C$. formosanus than are sticky traps. It is likely that new reproductive pairs may have established themselves in at least a 3- to 5-squaremile area of La Mesa.

In 1997, the number of alates trapped outside the core baited area dramatically increased, suggesting other active $C$. formosanus infestations (table 1). A new infestation was located approximately 200 feet beyond a steep, granite rock hillside north of the core area. The geological separation between sites makes it unlikely that the new infestation was ever directly connected with the original colony. It is likely that the new colony is a secondary infestation resulting from alate swarming from the original area. A

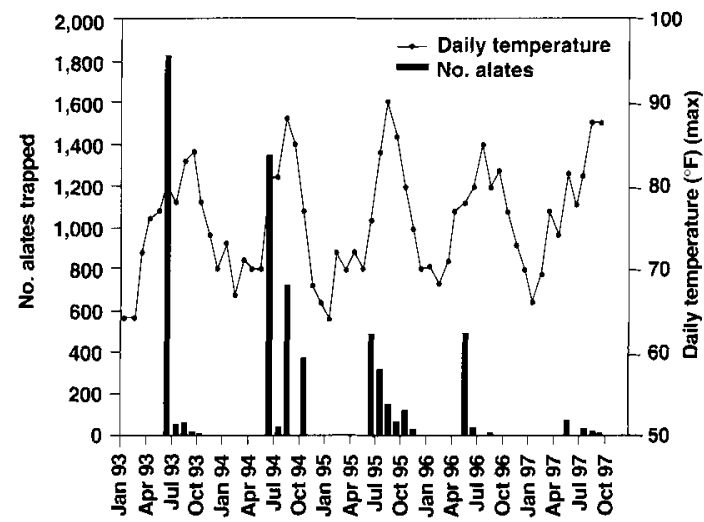

Fig. 2. The number of alate Formosan subterranean termites trapped in La Mesa within a 200-yard radius of the original infestation. 
pest control operator who first found the secondary population indicated the termites had actually been active in the structure nearly 2 years before our application of bait material in the nearby core area. The worker termites ( $3.39 \pm 0.404 \mathrm{mg}, \mathrm{n}=72$ ) from the new find are significantly smaller than similar stages collected from the original core area $(4.27 \pm 0.09 \mathrm{mg}, \mathrm{n}=$ 50, Atkinson et al. 1993; $\mathrm{t}$-test, ts = $50.29, P<0.02$ ). Besides the difference in worker size (Grace et al. 1995), the long distances between properties where alates have been recently captured suggest that there are at least two colonies in the same neighborhood.

At this point at least five homes in the new infestation area have been damaged by $C$. formosanus. Damage to some has been extensive, with treatment and repair costs totaling tens of thousands of dollars. All five homes have been fumigated for aboveground C. formosanus. The homes have also received ground treatment with termiticide and have had commercial bait installed. An effective remedial strategy to eliminate Formosan subterranean termites in California has not yet been developed. Our research program in La Mesa has been discontinued owing to lack of funding. However, alate monitoring should be continued and expanded to detect the geographic spread of this destructive pest and to serve as an early warning system to alert homeowners and professional pest control operators of impending problems.

M.K. Rust is Professor and Entomologist, and D.A. Reierson and E.O. Paine are Staff Research Associates, Department of

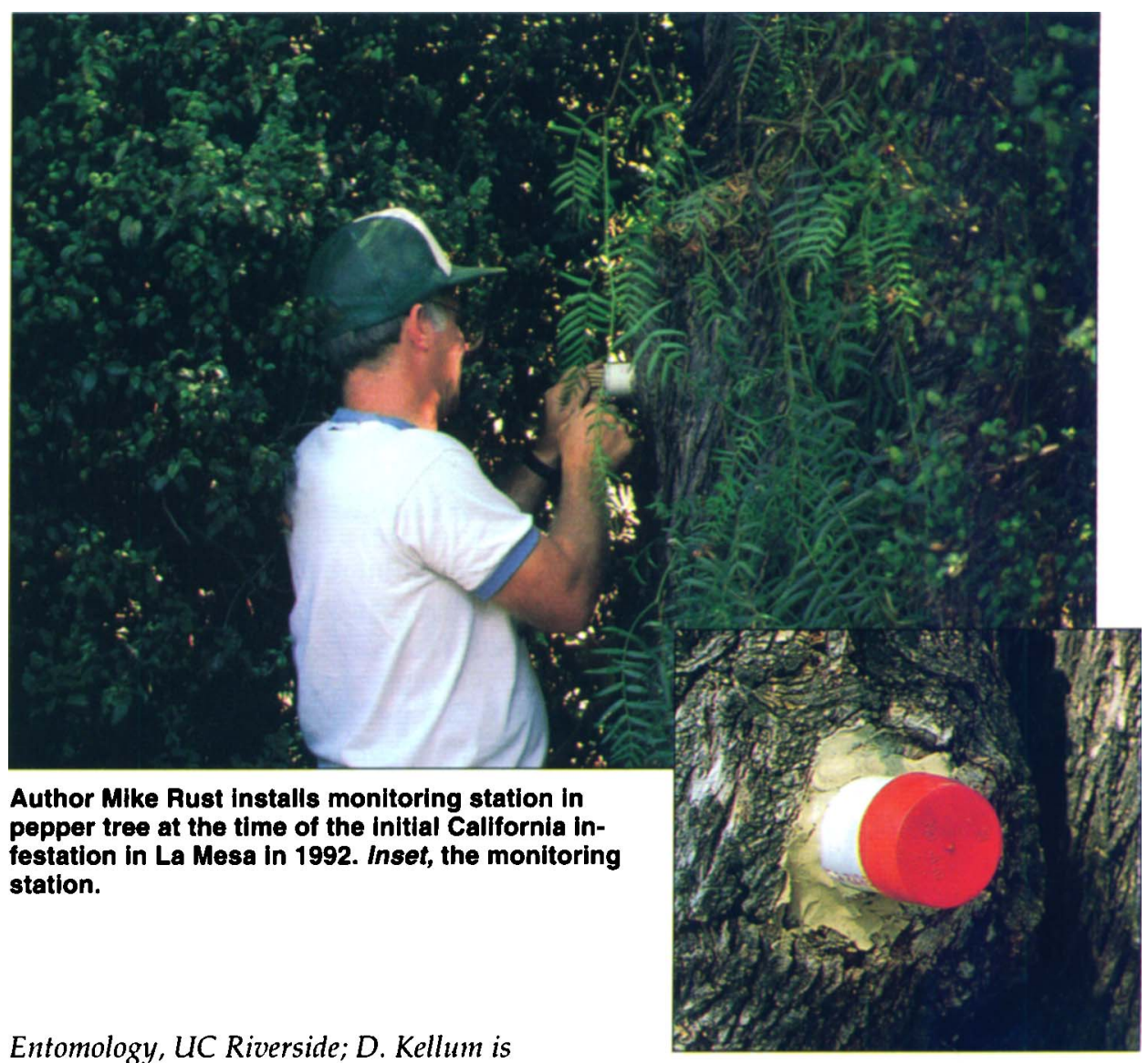

Senior Economic Entomologist, Department of Agriculture, San Diego County; and $K$. Haagsma is currently working as a private consultant to the pest control industry.

The authors would like to thank Joy Murray-Roseberry, Tim Breuninger and Cathymay Mangold with the County of San Diego, Department of Agriculture for their assistance in monitoring. We thank Chief Chris Carlson of the City of La Mesa Fire Department for the 1997 weather data for La Mesa.

They also thank DowElanco for providing financial support and the hexaflumeron bait used in the studies.

TABLE 1. Number of Formosan subterranean termite alates trapped within and beyond 200 yards of the original infestation in La Mesa

\begin{tabular}{|c|c|c|c|c|c|c|}
\hline \multirow[b]{2}{*}{ Year } & \multicolumn{3}{|c|}{ Core area ( $\leq 200$ yards) } & \multicolumn{3}{|c|}{ Outside the core area ( $>200$ yards) } \\
\hline & No. traps & $\begin{array}{l}\text { No. } \\
\text { alates }\end{array}$ & $\begin{array}{c}\text { No. traps } \\
\text { with alates }\end{array}$ & No. traps & $\begin{array}{c}\text { No. } \\
\text { alates }\end{array}$ & $\begin{array}{r}\text { No. traps } \\
\text { with alates }\end{array}$ \\
\hline 1993 & 41 & 2,206 & 30 & - & - & - \\
\hline 1994 & 40 & 1,840 & 33 & 54 & 627 & 44 \\
\hline 1995 & 35 & 875 & 25 & 49 & 703 & 30 \\
\hline 1996 & 36 & 544 & 16 & 49 & 93 & 17 \\
\hline 1997 & 17 & 113 & 8 & 42 & 2,535 & 26 \\
\hline
\end{tabular}

Core area defined as within 200 yards of the original (1992) identified site of infestation.

\section{References}

Atkinson TH, Rust MK, Smith JL. 1993. The Formosan subterranean termite, Coptotermes formosanus Shiraki (Isoptera: Rhinotermitidae), established in California. Pan-Pac Entomol 69: 111-13.

Grace JK, Yamamoto RT, Tamashiro M. 1995. Relationship of individual worker mass and population decline in a Formosan subterranean termite colony (Isoptera: Rhinotermitidae). Environ Entomol 24: 1258-62.

Haagsma K, Rust MK, Reierson DA,

Atkinson TH, Kellum D. 1995. Formosan subterranean termite established in California. Cal Ag 49: 30-3.

Higa SY. 1981. Flight, colony foundation, and development of the gonads of the primary reproductives of the Formosan subterranean termite, Coptotermes formosanus Shiraki. Ph. D. diss., Univ. Hawaii, Honolulu, HI.

Su N-Y. 1994. Field evaluation of a hexaflumeron bait for population suppression of subterranean termites (Isoptera: Rhinotermitidae). J Econ Entomol 87: 389-97.

Su N-Y, Tamashiro M. 1987. An overview of the Formosan subterranean termite (Isoptera: Rhinotermitidae) in the world, p 3-15. In M Tamashiro and N-Y Su (eds.), Proceed. Int. Symp. on the Formosan subterranean termite. Hawaii Institute of Trop. Agric. and Human Resources, Research Ext. Series 083 . 